\title{
Parental influences on children's mental health: the bad and the good sides of it
}

\author{
Maria Melchior $^{1} \cdot$ Judith van der Waerden $^{1}$
}

Published online: 25 July 2016

(C) Springer-Verlag Berlin Heidelberg 2016

Children's behavior and psychopathology risk can be influenced by parental characteristics, including socioeconomic position [1-4], migrant status, [5] and mental health [6-9], as well as parenting skills and sensitivity to children's needs [10]. Identifying characteristics that are most strongly associated with children's outcomes, and in particular those that are amenable to change, may benefit child mental health. As shown by interventional research, improving parenting practices is one way in which mental health problems can be addressed.

Two articles published in this month's issue of ECAP specifically highlight the importance of considering children's mental health in the context of their parents' characteristics. In a study conducted among 757 children referred to mental health clinics set in Amsterdam and in Rotterdam, Middeldorp et al. examined the prevalence of mental health difficulties among parents of consulting children. Among children, the most frequent diagnoses were Attention-deficit/hyperactivity disorder (ADHD) (35\%), anxiety (21\%) and autism spectrum disorders (22\%), behavioral disturbances $(10 \%)$, with some children presenting more than one disorder. Overall, $25 \%$ of parents had high levels of psychological difficulties with internalizing problems and symptoms of ADHD being the most frequent (respectively 20 and $10 \%$ ) [11]. One of the important findings of this study is that paternal characteristics-particularly symptoms of depression and ADHD_-were systematically associated with offspring outcomes to a similar extent as

Maria Melchior

maria.melchior@inserm.fr

Sorbonne Universités, UPMC Univ Paris 06, INSERM, Institut Pierre Louis d'Epidémiologie et de Santé Publique (IPLESP UMRS 1136), 75012 Paris, France maternal mental health difficulties, bringing forward the importance of involving fathers as much as possible in studies as well as interventions aiming to improve children's mental health $[9,12]$.

Another original observation is that parental anxiety (particularly the mother's) is a key predictor of offspring outcomes. An emerging literature shows that maternal anxiety identified as early as pregnancy predicts maternal long-term mental health [13] and offspring development $[14,15]$. However, while depression tends to be investigated and addressed in future parents, symptoms of anxiety receive much less attention. Overall, this study suggests that parents of youths who receive mental health treatment have high levels of frequent mental health symptoms. Even though the direction of this association is unclear, and children's behavior can influence parents' mental health, addressing parents' mental health needs can benefit offspring outcomes. To date, this has been shown in randomized controlled trials testing the effectiveness of depression treatment [8]. Data provided by Middeldorp et al. as well as other authors [16] suggest that interventions addressing parental anxiety should also be systematically evaluated.

As stated above, offspring characteristics may also shape the parent-child relationship, further influencing children's well-being [17]. Nevertheless, evidence from controlled trials indicates that positive changes in parenting can lower levels of behavioral difficulties in the offspring [18], implying parent-child interactions can be modified independently of children's behavior. In a randomized intervention trial conducted among 151 parentchild dyads, Schwenck et al. ask whether parent training can be effective in improving outcomes among high-risk children who receive inpatient psychiatric treatment [19]. The intervention, designed to be easily implemented and 
universal (open groups for parents of children with different types of difficulties) was delivered over the course of five sessions over 5 weeks. Overall, the authors found no effect on offspring behavior, however parents reported better mental health and parenting skills than the control group. Importantly, a proportion of parents of hospitalized youths themselves had mental health problems: $25 \%$ had symptoms at the time of the study, and approximately $40 \%$ had a history of psychotherapy and pharmaceutical treatment. Over a longer follow-up period, such improvements in parental mental health and family interactions-if sustained-could contribute to improvements in children's well-being. Additional intervention studies rigorously testing different components of parenting interventions with regard to children and adolescents' long-term outcomes are much needed.

This issue of ECAP also includes a Letter to the Editor that highlights the need for diagnostic and treatment tools for migrant and refugee children fleeing situations of conflict or extreme poverty with (or sometimes without) their families [20]. As highlighted by the authors, in Europe the needs of children who are resettled in the context of an armed conflict or who migrate in traumatizing conditions, are largely overlooked. This is in part because of insufficient mental health treatment opportunities for this particular population, but also because of contextual barriers to care. In a study we recently conducted among a population of homeless parents and children living in Paris-many of whom were migrant and came from areas of armed conflict-families' residential instability and difficult access to translation services made appropriate mental health care unlikely even when it was in principle available [21]. As a result, the most vulnerable children are those least likely to access treatment in case of psychological difficulties, in a health system that aims to be universal [22]. Moreover, in situations of conflict and severe material deprivation, parents are also at high risk of experiencing mental health problems, putting children from these highly vulnerable groups at additional risk of emotional and behavioral difficulties [21, 23].

Strengthening families may be one of the most propitious ways of preventing psychological difficulties in children and their parents, as well as improving symptoms among those who already experience emotional or behavioral problems. This is not an easy task, requiring intersectorial collaboration of mental health specialists in different areas (across child and adult services) with professionals in the fields of education, social work or rehabilitation. Much remains to be uncovered about the characteristics of parents and children at risk as well as optimal ways of addressing their needs in a timely manner. Articles published in this month's issue of ECAP give some lead on ways to move forward: search for parents' frequent and subclinical symptoms (e.g. anxiety), evaluate fathers, and pay special attention to children who are migrant.

\section{References}

1. Boe T, Overland S, Lundervold AJ, Hysing M (2012) Socioeconomic status and children's mental health: results from the Bergen Child Study. Soc Psychiatry Psychiatr Epidemiol 47:1557-1566

2. Costello EJ, Compton SN, Keeler G, Angold A (2003) Relationships between poverty and psychopathology: a natural experiment. J Am Med Assoc 290:2023-2029

3. Flouri E, Tzavidis N, Kallis C (2010) Adverse life events, area socioeconomic disadvantage, and psychopathology and resilience in young children: the importance of risk factors' accumulation and protective factors' specificity. Eur Child Adolesc Psychiatry 19:535-546

4. Jansen PW, Raat H, Mackenbach JP, Jaddoe VW, Hofman A, Verhulst FC et al (2009) Socioeconomic inequalities in infant temperament: the Generation R Study. Soc Psychiatry Psychiatr Epidemiol 44:87-95

5. Belhadj KE, Koglin U, Petermann F (2014) Emotional and behavioral problems in migrant children and adolescents in Europe: a systematic review. Eur Child Adolesc Psychiatry 23:373-391

6. van der Waerden J, Galéra CD, Larroque B, Saurel-Cubizolles M-J, Sutter-Dallay A-L, Melchior M (2015) Trajectories of maternal depression and children's behavior at age five: the EDEN birth cohort study. J Pediatr 166:1440-1448

7. Ramchandani PG, Stein A, O'Connor TG, Heron J, Murray L, Evans J (2008) Depression in men in the postnatal period and later child psychopathology: a population cohort study. J Am Acad Child Adolesc Psychiatry 47:390-398

8. Wickramaratne P, Gameroff MJ, Pilowsky DJ, Hughes CW, Garber J, Malloy E et al (2011) Children of depressed mothers 1 year after remission of maternal depression: findings from the STAR*D-Child study. Am J Psychiatry 168:593-602

9. Kvalevaag AL, Ramchandani P, Hove O, Assmus J, EberhardGran M, Biringer E (2013) Paternal mental health and socioemotional and behavioral development in their children. Pediatrics 131:e463-e469

10. Flouri E, Midouhas E, Joshi H, Tzavidis N (2015) Emotional and behavioural resilience to multiple risk exposure in early life: the role of parenting. Eur Child Adolesc Psychiatry 24:745-755

11. Middeldorp CM, Wesseldijk LW, Hudziak JJ, Verlhust FC, Lindauer RJ, Dieleman GC (2016) Parents of children with psychopathology: psychiatric problems and the association with their child's problems. Eur Child Adolesc Psychiatry. doi:10.1007/ s00787-015-0813-2

12. Panter-Brick C, Burgess A, Eggerman M, McAllister F, Pruett K, Leckman JF (2014) Practitioner review: engaging fathersrecommendations for a game change in parenting interventions based on a systematic review of the global evidence. J Child Psychol Psychiatry 55:1187-1212

13. van der Waerden J, Galéra CD, Saurel-Cubizolles M-J, SutterDallay A-L, Melchior M (2015) Predictors of persistent maternal depression trajectories in early childhood: results from the EDEN mother-child cohort study in France. Psychol Med 45:1999-2012

14. Ibanez G, Bernard JY, Rondet C, Peyre H, Forhan A, Kaminski $M$ et al (2015) Effects of antenatal maternal depression and anxiety on children's early cognitive development: a prospective cohort study. PLoS One 10:e0135849 
15. O'Connor TG, Heron J, Glover V (2002) Antenatal anxiety predicts child behavioral/emotional problems independently of postnatal depression. J Am Acad Child Adolesc Psychiatry 41:1470-1477

16. Ginsburg GS, Drake KL, Tein JY, Teetsel R, Riddle MA (2015) Preventing onset of anxiety disorders in offspring of anxious parents: a randomized controlled trial of a family-based intervention. Am J Psychiatry 172:1207-1214

17. Flouri E, Buchanan A (2003) The role of father involvement in children's later mental health. J Adolesc 26:63-78

18. Havighurst SS, Kehoe CE, Harley AE (2015) Tuning into teens: improving parental responses to anger and reducing youth externalizing behavior problems. J Adolesc 42:148-158

19. Schwenck C, Schneider W, Reichert A (2015) Universal parent training as a supplement to inpatient treatment for children and adolescents. Eur Child Adolesc Psychiatry. doi:10.1007/ s00787-015-0810-5
20. Gadeberg AK, Norredam M (2016) Urgent need for validated trauma and mental health screening tools for refugee children and youth. Eur Child Adolesc Psychiatry. doi:10.1007/ s00787-016-0837-2

21. Roze M, Vandentorren S, Vuillermoz C, Chauvin P, Melchior M (2016) Emotional and behavioral difficulties in children growing up homeless in Paris. Results of the ENFAMS survey. Eur Psychiatry. doi:10.1016/j.eurpsy.2016.05.001

22. Nay O, Bejean S, Benamouzig D, Bergeron H, Castel P, Ventelou B (2016) Achieving universal health coverage in France: policy reforms and the challenge of inequalities. Lancet 387(10034):2236-2249

23. Panter-Brick C, Grimon M, Eggerman M (2014) Caregiver-child mental health: a prospective study in conflict and refugee settings. J Child Psychol Psychiatry 55:313-327 